\title{
Correction to: From hermit crabs to humus: Heesoon Bai's contributions to cultural studies in science education
}

\author{
David Chang ${ }^{6} \cdot$ Charles Scott $^{2} \cdot$ Hartley Banack ${ }^{1}$ Lee Beavington ${ }^{5,6} \cdot$ Tom Culham $^{7}$. \\ Thomas Falkenberg ${ }^{8} \cdot$ Michael Link $^{4} \cdot$ Marcia McKenzie $^{9} \cdot$ Louise St. Pierre $^{3}$. \\ Allen $\mathrm{Yee}^{6} \cdot$ Steven Zhao ${ }^{6}$
}

Published online: 1 September 2021

() The Author(s), under exclusive licence to Springer Nature B.V. 2021

\section{Correction to: Cultural Studies of Science Education https://doi.org/10.1007/s11422-021-10055-7}

In the original publication of the article, the last author name Steven Zhao was incorrectly written as Steven Zhang. This has been corrected with this correction.

The original article has been corrected.

Publisher's Note Springer Nature remains neutral with regard to jurisdictional claims in published maps and institutional affiliations.

The original article can be found online at https://doi.org/10.1007/s11422-021-10055-7.

David Chang

dchangaccord@gmail.com

1 School of Education, University of Northern British Columbia, Prince George, Canada

2 Faculty of Education, Simon Fraser University, Burnaby, Canada

3 Faculty of Design + Dynamic Media, Emily Carr University of Art + Design, Vancouver, Canada

4 Faculty of Education, University of Winnipeg, Winnipeg, Canada

5 Kwantlen University, Surrey, Canada

6 Faculty of Education, Simon Fraser University, Burnaby, Canada

7 Beedie School of Business, Simon Fraser University, Burnaby, Canada

8 Faculty of Education, University of Manitoba, Winnipeg, Canada

9 College of Education, University of Saskatchewan, Saskatoon, Canada 